\title{
Abdominal Wall and Intra Pelvic Hematoma Presenting as Abdominal Pain after Short Course of Antibiotics in Patients on Long Term Warfarin Therapy
}

Kandegedara Ruwana Munasinghe ${ }^{1^{*}}$, Gallage Chandima Amarasena ${ }^{2}$, Naomali Lalani Amarasena ${ }^{1}$, Jagath Indranath Parakrama Herath ${ }^{1}$ and Harshana Dilan Samarasinghe ${ }^{1}$

${ }^{1}$ Advanced Cardiology Unit, Sri Jayewardenepura Hospital, Sri Lanka

${ }^{2}$ Cardiothoracic Unit, National Hospital of Sri Lanka, Sri Lanka

\begin{abstract}
Warfarin is the most commonly used anticoagulant in clinical practice. Despite its advantages it has serious side effects mainly bleeding due to narrow therapeutic range and several drug and food interactions. Spontaneous abdominal haemorrhage is one of the rare bleeding manifestations of it. Concomitant use of commonly used antibiotic are associated with an increased risk of bleeding among patients receiving warfarin.

We report two patients who presented with abdominal pain, later confirmed as abdominal wall and intraabdominal hematoma by computed tomography of abdomen. Both of them were had concomitant use of antibiotics along with warfarin prior to this clinical presentation.

We highlight the importance of making a high degree of suspicion on abdominal haemorrhage in patients with warfarin treatment when presented as abdominal abdomen. We also emphasized the consideration of drug interaction of warfarin before prescribing other medication as well as close monitoring of INR during that period.
\end{abstract}

\section{Introduction}

Warfarin, the most commonly used anticoagulant worldwide, is indicated for the prevention of systemic embolism in patients with prosthetic heart valves, atrial fibrillation and for the primary and secondary prevention of venous thromboembolism $[1,2]$.

Even though warfarin is efficient drug for the prevention of thrombo - embolism it is one of the most common drugs which have serious side effect mainly causing bleeding ranging from minor to fatal haemorrhagic manifestations [3-5]. Spontaneous abdominal wall and intra-abdominal hematoma is a rare bleeding manifestation of anticoagulant therapy.

All commonly used classes of antibiotics (Azole antifungals, Macrolides, Quinolones, Cotrimoxazole, Penicillin and Cephalosporin) are associated with an increased risk of bleeding among patients receiving warfarin $[6,7]$.

We report two patients who presented with spontaneous abdominal wall and intra-abdominal hematoma with concomitant use of warfarin and antibiotics.

\section{Case History 01}

A 57 year old woman, on warfarin treatment following mitral valve replacement, presented with diffuse continuous mild to moderate abdominal pain and distension for 3-4 days. On the $4^{\text {th }}$ day of symptom onset she noticed a dark pigmentation over the anterior abdominal wall.

She was able to maintain the INR in the therapeutic range most of the time during last 7 years. (Last INR level 1 month back was 2.6). She was prescribed Co amoxyclave $625 \mathrm{mg}$ thrice daily, prednisolone 10 mg thrice daily and vitamin C 1 tablet thrice daily for respiratory tract infection 4 days prior to onset of symptoms.

On physical examination temperature $37.4^{\circ} \mathrm{C}$, blood pressure $120 / 79 \mathrm{~mm} \mathrm{Hg}$, pulse rate 68 beats/min, and respiratory rate 12 breaths/min. A firm mass was palpable over the upper abdominal wall and it was not tender. She had ecchymosis in anterior abdominal wall (Figure 1). There was no evidence of free fluid on percussion.

Abdominal ultrasound revealed presence of multiple anterior abdominal wall masses and large intra pelvic hematoma measuring $10.9 \mathrm{~cm} \times 9.8 \mathrm{~cm} \times 9.8 \mathrm{~cm}$ adjacent to urinary bladder on right side. Computed tomography (CT) scan of abdomen confirms organized hematomas within the right rectus abdominis muscle in multiple levels (Figure 2) and a large hematoma in the pelvis $(11.7 \mathrm{~cm} \times 6.6 \mathrm{~cm} \times 11$ $\mathrm{cm}$ ) in to the right side of the urinary bladder displacing it (Figure 3).

Her other investigations on admission revealed INR level of 6.0, Hemoglobin level of $8.2 \mathrm{~g} / \mathrm{dl}$ and serum creatinine of $1.53 \mu \mathrm{mol} / \mathrm{L}$. Her platelet count, APTT, liver functions were within normal range.

Immediate suspension of oral warfarin treatment was done. She was transfused two pints of blood and pain managed with simple analgesia. Abdominal swelling resolved gradually in the following 4-5 days and no surgical intervention was needed. Her INR level came to therapeutic range 4 days after admission. Warfarin was restarted in smaller dose and adjusted according to the INR level. Her INR one

*Corresponding author: Kandegedara Ruwana Munasinghe, Advanced Cardiology Unit, Sri Jayewardenepura Hospital, Sri Lanka, Tel: 94718339509 ; E-mail: ruwanm2001@yahoo.com

Received August 19, 2016; Accepted January 11, 2016; Published January 18 2016

Citation: Munasinghe KR, Amarasena GC, Amarasena NL, Herath JIP, Samarasinghe HD (2016) Abdominal Wall and Intra Pelvic Hematoma Presenting as Abdominal Pain after Short Course of Antibiotics in Patients on Long Term Warfarin Therapy. Cardiovasc Pharm Open Access 5: 170. doi:10.4172/23296607.1000170

Copyright: (c) 2016 Munasinghe KR, et al. This is an open-access article distributed under the terms of the Creative Commons Attribution License, which permits unrestricted use, distribution, and reproduction in any medium, provided the original author and source are credited. 
Citation: Munasinghe KR, Amarasena GC, Amarasena NL, Herath JIP, Samarasinghe HD (2016) Abdominal Wall and Intra Pelvic Hematoma Presenting as Abdominal Pain after Short Course of Antibiotics in Patients on Long Term Warfarin Therapy. Cardiovasc Pharm Open Access 5: 170. doi:10.4172/2329-6607.1000170

Page 2 of 3

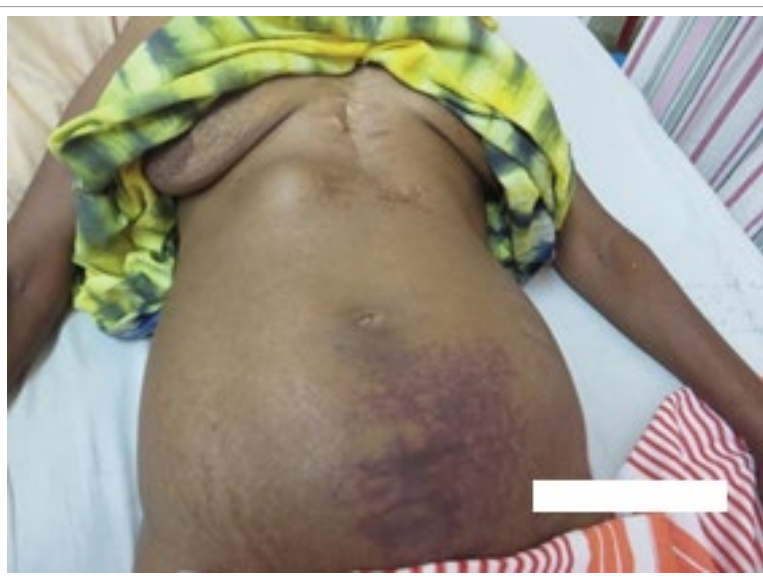

Figure 1: Right upper abdominal wall swelling and anterior abdominal wall ecchymosis.
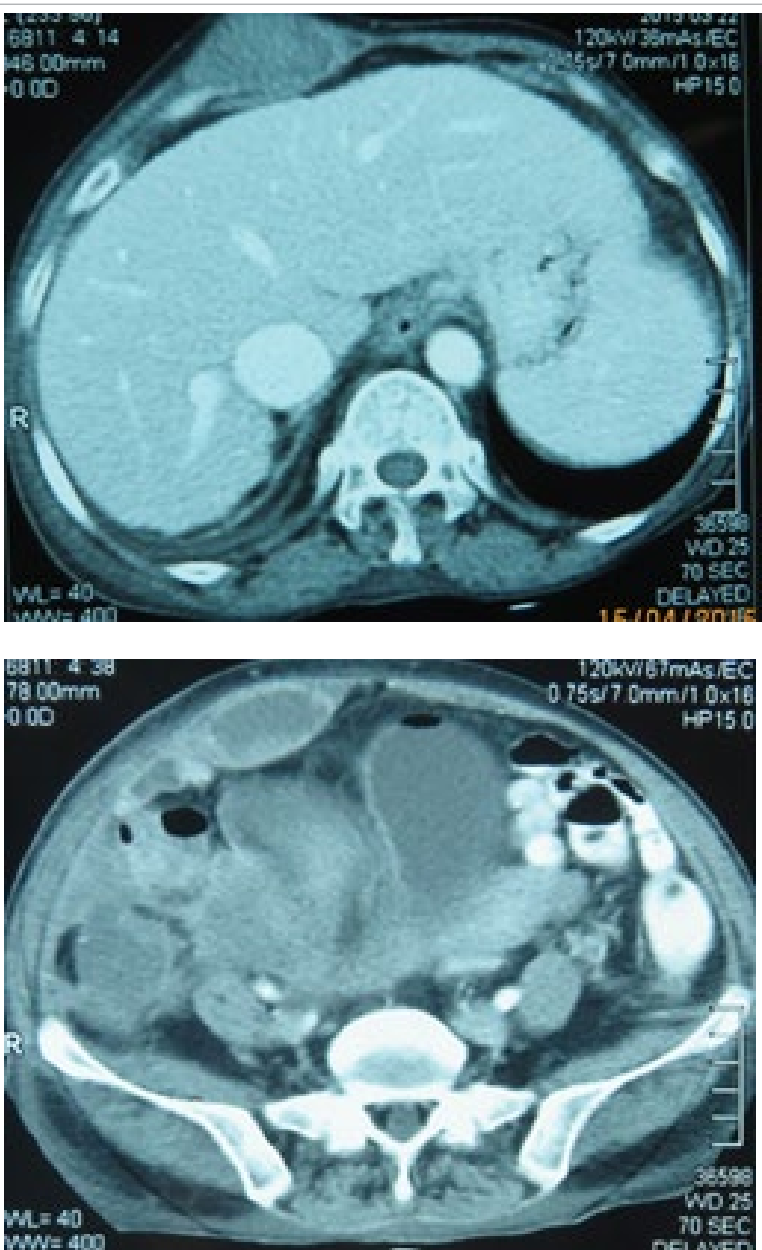

Figure 2: Computed tomography images showed organized hematomas within the right rectus abdominis muscle in multiple levels.

week after admission was 2.6 and hemoglobin and serum creatinine levels achieved normal values.

\section{Case History 02}

A 58 year old female patient, with a 8-year history of dyslipidemia, essential hypertension and diabetes mellitus presented with localized anterior abdominal pain and swelling for 2 days duration. No history of trauma, urinary or bowel symptoms. Her long term medication includes atorvastatin $20 \mathrm{mg}$ daily, losartan $25 \mathrm{mg}$ bd, metformin 500 $\mathrm{mg}$ tds and warfarin $3.5 \mathrm{mg}$ daily for last 5 years following prosthetic mitral valve replacement. She was prescribed co amoxyclave $625 \mathrm{mg}$ tds, salbutamol $2 \mathrm{mg}$ tds and piriton $4 \mathrm{mg}$ nocte for respiratory tract infection 5 days prior to admission.

Physical examination was unremarkable except that moderate anemia and anterior abdominal wall lump measuring about $10 \mathrm{~cm} \times$ $8 \mathrm{~cm}$.

Laboratory investigation on admission showed INR level 10.0, Hemoglobin $6.4 \mathrm{~g} / \mathrm{dl}$ with a hematocrit value of $61 \%$.WBC count and platelet count, renal functions, liver functions and electrolytes were within normal range. Her abdominal ultrasound scan revealed hypo echogenic mass in anterior abdominal wall, which was confirmed as $8.1 \mathrm{~cm} \times 4.3 \mathrm{~cm} \times 12 \mathrm{~cm}$ (sagittal) size intra muscular hematoma within the right rectus abdominis muscle extending up to the pubic symphysis level in computed tomography (CT) scan (Figure 4).

She was managed conservatively and warfarin treatment withheld with daily monitoring of INR level. She was transfused 3 pints of blood during hospital stay.

Her INR level came to therapeutic range 4 days after stopping it. Warfarin treatment was reinitiated as small dose with adjustment of the dose during hospital stay. Her pre discharge INR level was 2.6 and hemoglobin level was $12.1 \mathrm{~g} / \mathrm{dL}$

\section{Discussion}

Warfarin, the most commonly used anti-coagulant worldwide [1], is mediated through inhibition of vitamin $\mathrm{K}$ dependent gamma carboxylation of coagulation factors II, VII, IX, and X [8].

It is indicated for the prevention of systemic embolism in patients with prosthetic heart valves or atrial fibrillation and for the primary and secondary prevention of venous thromboembolism [2,9]. Despite its high clinical indication and efficacy serious side effects mainly causing bleeding led to its underutilization.

The most important factor causing the risk of bleeding is the intensity of anticoagulant therapy [5]. There are several factors including lot of drug and food interact the action of warfarin leading over anti coagulation, under anticoagulation or increased bleeding independent of changes in INR value [10,11]. Mechanisms associated with interaction include altered platelet action, alteration of vitamin $\mathrm{K}$ metabolism and alteration of warfarin metabolism. Commonly used antibiotics are well known to cause increased INR [6,7].

Although penicillins have not been shown to interact with warfarin [12], isolated few cases have been reported, particularly with broadspectrum penicillins $[13,14]$. Our both patients were on Co- amoxyclav for respiratory tract infection few days prior to development of abdominal bleeding.

Spontaneous abdominal wall hematomas are an uncommon cause of acute abdominal pain and are often misdiagnosed. It can also present as abdominal wall mass with or without ecchymosis $[15,16]$.

CT scan can accurately confirm the diagnosis of abdominal wall and intra-abdominal hematoma [1].

The mainstay of management of abdominal wall hemorrhages is conservative including bed rest and analgesics. However, surgical treatment may indicate. In our patients the first measure was the 
Citation: Munasinghe KR, Amarasena GC, Amarasena NL, Herath JIP, Samarasinghe HD (2016) Abdominal Wall and Intra Pelvic Hematoma Presenting as Abdominal Pain after Short Course of Antibiotics in Patients on Long Term Warfarin Therapy. Cardiovasc Pharm Open Access 5: 170. doi:10.4172/2329-6607.1000170

Page 3 of 3

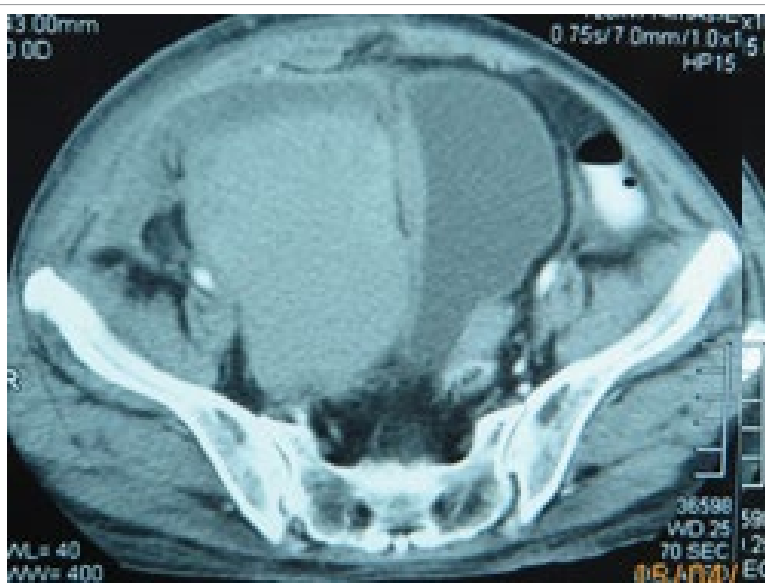

Figure 3: Computed tomography images showed a large hematoma in the pelvis $(11.7 \mathrm{~cm} \times 6.6 \mathrm{~cm} \times 11 \mathrm{~cm})$ in to the right side of the urinary bladder displacing it.

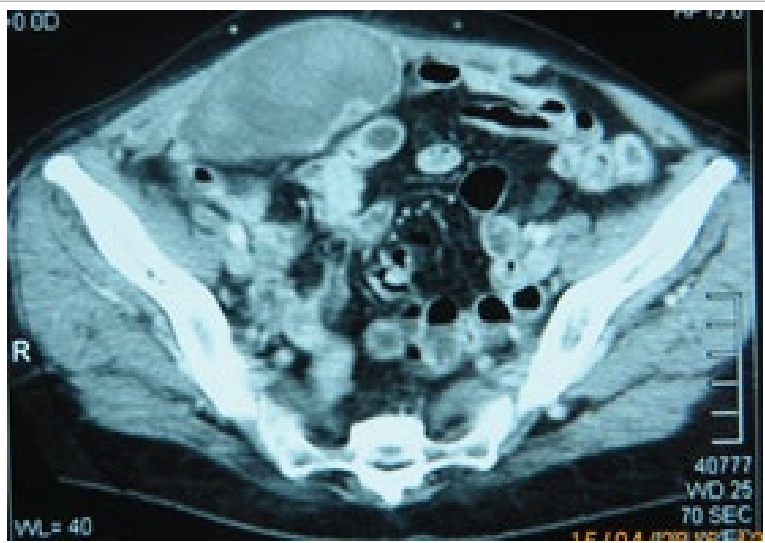

Figure 4: Computed tomography images showed $8.1 \mathrm{~cm} \times 4.3 \mathrm{~cm} \times 12 \mathrm{~cm}$ (sagittal) size intra muscular hematoma within the right rectus abdominis muscle.

immediate suspension of oral anticoagulants with close monitoring of INR value and conservative management. None of them needed surgical treatment.

\section{Conclusion}

Keeping a high suspicion of abdominal haemorrhage is important if a patient on long term warfarin therapy presented with abdominal pain. Clinicians must consider the drug interaction of warfarin before prescribing other medication and need to monitor INR level closely during concomitant drug usage period.

\section{References}

1. Lemos Silva R, Carvalho de Sousa J, Calisto C, Braz Nogueira JM, Ravara L (2007) Oral anticoagulant therapy. Fundamentals, clinical practice and recommendations. Rev Port Cardiol 26: 769-788.

2. Keeling D, Baglin T, Tait C, Watson H, Perry D, et al. (2011) Guidelines on oral anticoagulation with warfarin - fourth edition. Br J Haematol 154: 311-324.

3. Pirmohamed M (2006) Warfarin: almost 60 years old and still causing problems $\mathrm{Br} \mathrm{J}$ Clin Pharmacol 62: 509-511.

4. Landefeld CS, Beyth RJ (1993) Anticoagulant-related bleeding: clinical epidemiology, prediction and prevention. Am J Med 95: 315-328.

5. Coon WW, Willis PW 3rd (1974) Hemorrhagic complications of anticoagulant therapy. Arch Intern Med 133: 386-392.

6. Rice PJ, Perry RJ, Afzal Z, Stockley IH (2003) Antibacterial prescribing and warfarin: a review. Br Dent J 194: 411-415.

7. Baillargeon J, Holmes HM, Lin YL, Raji MA, Sharma G, et al. (2012) Concurrent use of warfarin and antibiotics and the risk of bleeding in older adults. Am J Med 125: 183-189.

8. Ansell J, Hirsh J, Hylek E (2008) Pharmacology and management of the vitamin $\mathrm{K}$ antagonists: American collage of chest physicians' evidence based clinical practice guidelines (8th edition). Chest 133: 160S-198S.

9. January CT, Wann LS, Alpert JS, Calkins H, Cigarroa JE, et al. (2014) AHA ACC/HRS Guideline for the Management of Patients With Atrial Fibrillation: A Report of the American College of Cardiology/American Heart Association Task Force on Practice Guidelines and the Heart Rhythm Society. Circulation 130: e199-267.

10. Holbrook AM, Pereira JA, Labiris R, McDonald $H$, Douketis JD, et al. (2005) Systematic overview of warfarin and its drug and food interactions. Arch Intern Med 165: 1095-1106.

11. Juurlink DN (2007) Drug interactions with warfarin: what clinicians need to know. CMAJ 177: 369-371.

12. Zhang Q, Simoneau G, Verstuyft C, Drouet L, Bal dit Sollier C, et al. (2011) Amoxicillin/clavulanic acid-warfarin drug interaction: a randomized controlled trial. Br J Clin Pharmacol 71: 232-236.

13. Kelly M, Moran J, Byrne S (2005) Formation of rectus sheath hematoma with antibiotic use and warfarin therapy: a case report. Am J Geriatr Pharmacother 3: 266-269.

14. Larsen TR, Gelaye A, Durando C (2014) Acute warfarin toxicity: An unanticipated consequence of amoxicillin/clavulanate administration. Am J Case Rep 15: 45-48.

15. Masanori Shimodaira, Tomohiro Kitano, Minoru Kibata, Kumiko Shirahata (2013) An oblique muscle hematoma as a rare cause of severe abdominal pain: a case report. BMC Research Notes 6: 18.

16. Narum S, Solhaug V, Myhr K, Johansen PW, Brors O, et al. (2011) Warfarinassociated bleeding events and concomitant use of potentially interacting medicines reported to the Norwegian spontaneous reporting system. British Journal of Clinical Pharmacology 71: 254-262 